\title{
PASCUAL MADOZ E ILDEFONSO CERDA, DOS PIONEROS EN LA EPIFANIA DE LA URBANÍSTICA
}

\section{PASCUAL MADOZ AND ILDEFONSO CERDÁ: TWO PIONEERS IN THE URBANISTIC EPIPHANY}

\author{
García-Bellido y García de Diego, Javier \\ Dr. Arquitecto, urbanista. Dir. Gral. Urbanismo y Política de Suelo \\ Ministerio de Vivienda. Prof. asociado Escuela Técnica Superior de \\ Arquitectura de Barcelona - Universidad Politécnica de Cataluña. \\ Madrid, España.
}

Palabras Clave: génesis del urbanismo, financiación del urbanismo, Pascual Madoz, Idelfonso Cerdá, ensanches decimonónicos.

Palabras Clave: genesis of urbanism, financing of urbanism, Pascual Madoz, Idelfonso Cerdá, $19^{\text {th }}$ Century city extensions.

Resumen: En el año 2005 acabamos de conmemorar el 200 aniversario del nacimiento de Pascual MADOZ (1805-1870), con cuyo motivo hemos podido alumbrar una documentación inesperada que permite situarle como figura político-financiera muy relevante en los pasos iniciales del urbanismo moderno, señalando su convergencia con el padre y fundador indiscutido de la disciplina en toda Europa y el mundo: Ildefonso Cerdá.

La convergencia se establece en que, además de varias comuniones ideológicas entre los dos personajes (pertenecer al mismo partido liberal progresista, ser ambos de la Milicia Nacional, catalanistas de corazón, escritores y estadísticos, empresarios inmobiliarios y constructores de casas), Madoz dirige y edita en 1845-50 el voluminoso Diccionario geográficoestadístico-histórico de España, el más grandioso inventario de información municipal y cartográfica nunca producido hasta ahora, sacó adelante como Ministro de Hacienda la fundamental Ley General de Desamortización de 1855 y dirigió, impulsó y encarriló definitivamente la operación urbanística trascendental del derribo de las murallas de Barcelona en 1854, con una operación económico-financiera magistral, haciendo converger en una emisión de deuda pública en forma de préstamo hipotecario garantizado por el valor futuro de la edificabilidad potencial de los solares edificables, interconectando los aspectos políticos de oportunidad y emergencia social, con unas técnicas jurídicas y económico-financieras sorprendentes que marcaron los derroteros del urbanismo español posterior.

En esa coyuntura explosiva de la ruptura de los recintos amurallados del XIX en toda Europa, surge la poderosa cabeza sintética de Cerdá que integra el gobierno del espacio social como una ciencia moderna - la Urbanización, que luego llamaríamos Urbanismo- dando consistencia mutua a las disciplinas, hasta entonces inconexas, de la economía, el diseño y el derecho privado y administrativo en el espacio municipal, que Madoz había mezclado impensadamente con su operación financiera de emergencia al sacar el empréstito para financiar las obras del derribo de las murallas. 
Summary: The year 2005 marked the 200th anniversary of the birth of Pascual Madoz (18051870). In a commemoration of that event, we began an unexpected documentation that has allowed us to situate him as a very relevant political and financial figure in the initial rise of modern urbanism, indicating his union with the indisputable father and founder of the discipline in Europe and the wider world: Ildefonso Cerdá.

In addition to coinciding ideologically on a number of issues (belonging to the same liberal political party, both forming part of the National Militia, deeply rooted Catalonians, writers and statisticians, property businessmen and house constructors), the union was established between the two individuals through Madoz directing and publishing between 1845-50 the voluminous Geographical-statistical-historical dictionary of Spain, the most grandiose inventory of municipal and cartographic information ever to have taken place even up until now.

As the Minister of Finance, he promulgated the General Law of Disentitlement (1855). In addition he promoted, directed and guided the transcendental planning intervention leading to the demolition of Barcelona's walls in 1854, with a masterful economic-financial operation, channelling an emission of public debt in the form of mortgage loans guaranteed by the future value of the potential building of the land parcels, interconnecting the political aspects of opportunity and social emergency, with some surprising juridical and economic-financial techniques that marked the beginnings of the later Spanish urbanism.

In that explosive juncture of the rupture of the walled enclosures of 19th Century Europe, the powerful brilliance of Cerdá arose that would integrate the government of social space as a modern science - Urbanisation that would later be called Urbanism - integrating the until then different disciplines of economy, design, and private and administrative law in the municipal space, that Madoz had mixed without thinking with his emergency financial operation, when carrying out the public loan to finance the works of demolishing the walls.

\section{MADOZ y CERDÁ en el nacimiento de la Urbanística.}

$\S 1$ Dos personajes señeros en la historia del urbanismo moderno, y más concretamente de la Barcelona de mediados del siglo XIX, van a cruzar sus vidas y sus actuaciones históricas en momentos álgidos de la formación de la nueva disciplina, para dar un vuelco, cada uno desde su campo, a las prácticas rutinarias precedentes, tomando decisiones cruciales e innovando enfoques disciplinares ciertamente revolucionarios. Tanto, que marcaron la historia no sólo de la ciudad de Barcelona, sino de la construcción de la entera disciplina de la Urbanística moderna. Aquellos momentos fueron críticos, cuando las decisiones políticas atrevidas y la visión de ambiciosas metas profesionales rompieron la rutinaria tradición y crearon una inflexión en la línea del progreso del conocimiento y de la gestión incipiente sobre la ciudad.

Es entonces cuando la política y la práctica incipientes del, a la sazón, llamado 'trazado de nuevos caseríos' —o, más académicamente, 'arte de construcción de las ciudades' y que luego, ya en el siglo XX, llamaríamos Urbanismo (ver GARCíA-BELLIDO, 1994 y 2004)— dieran los primeros pasos para fecundar e integrar los dos pilares esenciales donde se apoya toda su práctica disciplinar moderna, a saber: (i) en la gestión jurídico-económico-financiera que responde al 'quién' paga y 'cuánto' se ha de pagar para hacer posible esa ciudad; y (ii) en la formalización del trazado y diseño del plano geométrico a realizar, que responde al 'dónde' y el 'cómo' morfológico de la ciudad en su territorio geográfica y socialmente determinado.

ACE, Vol.1, núm. 1, pp.4-28, 2006 | PASCUAL MADOZ E ILDEFONSO CERDA, DOS PIONEROS EN LA EPIFANIA DE LA URBANISTICA 
Precisamente preguntas que han de reunir al político / Prínceps gobernante — $\sin$ el cual nada es posible en el espacio por él gobernado de la ciudad y del territorio- junto con sus técnicos asesores o ejecutores que resuelvan las cuestiones precisas para lograr ese fin; pero técnicos que, asimismo, han de estar imbuidos de una poderosa voluntad creadora y movidos por ideales altruistas que les impulsen a innovar y progresar, a veces empujando seductores al político decisor, cuando no sea éste el que les incite a buscar las soluciones. El primero fue Pascual MADOZ y el segundo personaje fue lldefonso CERDÁ ( ${ }^{*}$ )

En este caso pude verse cómo se entrelazaron por diversos caminos un político y financiero, osado liberal y ferviente progresista, como MADOZ, y un ingeniero de caminos creador ambicioso y racionalista, también osado liberal y social-progresista, como CERDÁ.

§2. D. Pascual MAdoz IBÁÑEz (Pamplona, 17 de mayo de 1805 —no de 1806, como ponen todas sus biografías y al pie de su mausoleo-, Génova 11 de diciembre de 1870) fue toda su vida un político activo y convencido de la revolución liberal, monárquico, progresista, reformista, anticlerical, director-fundador del periódico "El Catalán", Gobernador militar del Valle de Arán, activo miembro de la Milicia Nacional, alcalde mayor interino de Barcelona, Diputado a Cortes 14 veces por Tremp (Lleida), proteccionista catalanista y activo defensor de los empresarios e industriales de su tierra de adopción, incluso representante de la patronal catalana "Junta de Fábricas". Llegó a lo más alto de su carrera política en el Bienio Progresista siendo Gobernador civil de Barcelona (63 días, del 8 de agosto al 21 octubre de 1854), cuando dirigió con éxito las medidas contra la epidemia de cólera morbo que azotó Barcelona, terció en las huelgas y lockouts de las selfactinas e impulsó y garantizó la financiación para el derribo de las murallas de Barcelona sobre las que se abrió el gran Eixample de CERDÁ, siendo nombrado hijo adoptivo de Barcelona aún en vida.

Fue MADOZ Presidente del Congreso de los Diputados (dic. 1854) y nombrado Ministro de Hacienda (enero 1855) con el Gobierno progresista de ESPARTERO, cuando sacó adelante su gran Ley General de Desamortización de $1^{\circ}$ de mayo de 1855 . ... y aún tuvo tiempo para elaborar, imprimir y vender los 16 tomos del Diccionario geográfico-estadístico-histórico de España y sus posesiones de Ultramar, monumental obra escrita por la que es más conocido, siendo renombrada como "El Madoz". Incluso fue un emprendedor promotor inmobiliario fundador de la sociedad "La Peninsular" (1859) construyendo varios centenares de viviendas. Hasta aquel mes de diciembre de 1870, en que fallece en Génova en acto de servicio público, cuando volvía del viaje como eminente comisionado por las Cortes españolas para ofrecer la Corona de España al DUQUE DE AOSTA, futuro rey AMADEO I DE SABOYA, rindiéndosele honores de capitán general en reconocimiento a su larga y recta vida pública. Se le erigió un digno mausoleo por suscripción popular en el cementerio de Montjuich, volcado sobre el azul del Mediterráneo, en el eje de la zona de Sant Oleguer 5, una de las más representativas de su escarpada y romántica topografía.

Tal vez sea MADOZ un ejemplo señero del hombre político socialmente comprometido del siglo XIX, del liberal "progresista puro, templado, constitucional y monárquico", como él se definió a sí mismo. El documentado libro del historiador Francisco Javier PAREDES ALONSO (1982), es de obligada consulta para todo el que quiera conocer su vida y a él se remite in totum.

Veamos cuáles fueron aquellas circunstancias excepcionales que entretejieron los destinos de MADOZ con el nacimiento de la urbanística moderna modelada con las manos del genial Ildefonso CERDÁ.

\footnotetext{
EI presente artículo es una revisión y reducción sustancial de GARCíA-BELLIDO (2005), concentrándose mejor en las dos figuras protagónicas.
} 
§3. Ildefonso CERDÁ (23 de diciembre de 1815, 21 de agosto de 1876, diez años menor, pues, que MADOZ), figura mucho más conocida ya hoy día en los círculos urbanísticos catalanes, españoles y europeos (tras haber podido superar la secular e ignominiosa campaña de ostracismo hasta los años 1970-80), no se metió en política activa nada más que esporádicamente, cuando su vocación social le llamaba para cooperar en momentos críticos del país y cuando podía participar en su línea progresista (vide per allia, ESTAPÉ, 1971; SORIA, 1979).

Desde 1848 CERDÁ fue absorbido en la mayor parte de su vida por los estudios urbanos. Así como la andadura política de MADOZ se iniciaría tempranamente hacia 1835, con 25 años, la de CERDÁ sería más tardía y a saltos, no antes de los 35 años (1850). Y, al igual que MADOZ ascendería al poder sólo en los dos períodos más progresistas de su época, CERDÁ sólo intervino en la política en el bienio progresista, 1854-55, y con la "Gloriosa" y la Primera República, 1868 y 1873. Entre una y otra se sumergió en su producción teórica y práctica de la ciencia de la "urbanización" que él acuñara, hasta la ruina de la hacienda familiar.

\section{Coincidencias vitales de Madoz y Cerdá.}

$\S 4$. Pueden agruparse esas concomitancias circunstanciales de las biografías de ambos personajes en torno a seis hechos biográficos que les hicieron coincidir, al menos:

1) Su militancia política activa en el partido liberal progresista, con una entrega total de MADOZ y sólo eventual en CERDÁ (Diputado a Cortes por Barcelona en la legislatura de junio 1851-diciembre 1852);

2) Su pertenencia a la Milicia Nacional, brazo militante del progresismo, con CERDÁ alcanzando el grado de Comandante, mientras MADOZ no dejaría de ser simple 'soldado';

3) Su catalanismo declarado, de adopción en MADOZ $\left({ }^{1}\right)$ y por familia de Sant Martí de Centelles en CERDÁ;

4) Su actitud científico-práctica ante las nuevas ciencias sociales (cuasi personificadas en la estadística urbana);

5) El cruce clave de sus vidas en torno al derribo de las murallas de Barcelona, sus intervenciones en paralelo en la huelga general de 1854, y el seguimiento del proyecto del ensanche;

6) Sus incursiones empresariales con "La Peninsular" el uno, y con "Fomento del Ensanche de Barcelona" el otro.

Dejando para el final en un apartado expreso lo más relevante para la historia del Urbanismo de estas conexiones biográficas entre CERDÁ y MADOZ, que fue sin duda, el protagonismo de ambos en torno al derribo de las murallas y el ensanche de Barcelona, véanse muy brevemente las demás vinculaciones históricas.

\footnotetext{
${ }^{1}$ El primer estudioso de CERDÁ, el economista Fabián ESTAPÉ, al hablar del tema de las murallas, recoge la postura de MADOZ de ser "radicalmente partidario" del derribo de las murallas y el ensanchamiento de Barcelona al defenderlas en la voz 'Barcelona' de su Diccionario: “... es preciso conceder la palabra a uno de sus principales artífices [del derribo]: me refiero a Pascual Madoz, el político español no catalán más vinculado a los intereses de Barcelona y de Cataluña en el pasado siglo" (ESTAPÉ, 1971: 141). Y más adelante añade: "En las primeras semanas del triunfo de la revolución [de julio de 1854] se procedió al relevo del gobernador civil de Barcelona; la delicada situación derivada del conflicto obrero aconsejó elegir a una figura política que se había destacado por su vinculación con los problemas catalanes, vinculación que no desmintió jamás a lo largo de su ulterior carrera política: me refiero a Pascual Madoz..." (ibidem:
}

ACE, Vol.1, núm. 1, pp.4-28, 2006 | PASCUAL MADOZ E ILDEFONSO CERDA, DOS PIONEROS EN LA EPIFANIA DE LA URBANISTICA 


\section{A) Diputados progresistas, catalanistas y amigos}

§5. Respecto a la primera circunstancia de la pertenencia de ambos al partido liberal progresista tuvo que ser la vinculación más perdurable, precisamente por anudarse en sus relaciones de correligionarios: MADOZ y CERDÁ formaron parte de una misma candidatura progresista por Barcelona en las elecciones del 31 de agosto de 1850 (legislatura que sólo duraría hasta abril de 1851), junto con Estanislao FIGUERES y Jacint Fèlix DOMENECH, aunque MADOZ se presentaba también por Lérida, sacando ambas actas, prefiriendo la de Lérida $\left({ }^{2}\right)$.

De esos primeros pasos de CERDÁ por las Cortes y su colaboración con MADOZ, consta que firmaron, junto a otros diputados, una proposición incidental el 23 de julio de 1851 y una enmienda el 29 del mismo en la discusión sobre el ferrocarril Aranjuez-Almansa (cfr. SoRIA, 1979: 53, n. 6). Sería en esa legislatura, cuando el 24 de julio CERDÁ se dirigiría por vez primera al Congreso de los Diputados para referirse al programa de obras públicas del Gobierno moderado de BRAVO MURILLO (DSC, 1851: II: 888-890; ESTAPÉ, 1971: 239-43).

§6. El trabajo del Diccionario de MADOZ y su estrecha vinculación con Francisco CoELLO DE PORTUGAL (1822-1898), coronel de ingenieros y autor del Atlas de España y sus Posesiones de Ultramar, formando una empresa que editaba y vendía conjuntamente ambos, pudo poner en contacto a MADOZ con CERDÁ también a través del autor del Atlas. La cartografía provincial y urbana de COELLO, realizada entre 1844-1846 y la publicación de sus primeras 18 hojas entre 1847 y 1853 y las 7 siguientes entre el 53 y el 59, permitieron hacer los primeros planos topográficos modernos con teodolitos ópticos de precisión de la historia $\left({ }^{3}\right)$; por lo que CERDÁ tuvo que conocer dichas técnicas topográficas para sus levantamientos de ingeniero civil (carreteras, canales, ferrocarriles que venía haciendo desde su título en 1841, no sólo el plano del llano de Barcelona, realizado entre 1854-55). Y, desde luego, tuvo en sus manos los resultados de los planos de CoELLo en aquellos años.

No es, pues, nada más que una hipótesis muy verosímil que CERDÁ y MADOZ también conectaran vía COELLO, liberal y amigo común, quien además intervino como cartógrafo en el plan de ferrocarriles de 1855, preparado cuando MADOZ era Ministro de Hacienda (ver QUIRÓs \& alii, 2005).

§7. En sus relaciones más científicas y menos políticas, MADOZ y CERDÁ tuvieron que coincidir también a través del economista Laureano FIGUEROLA Y BALLESTER (1816-1903), liberal progresista, autor de la Estadística de Barcelona en 1849 (primer trabajo estadístico sistemático que sería profusamente utilizado y resumido por CERDÁ en 1856 para su Monografía estadística), catedrático de Derecho Administrativo y de Economía Política desde 1847, antiesclavista decidido, Vicepresidente de la Sociedad Abolicionista Española desde su fundación en 1865, librecambista a ultranza, varias veces Ministro de Hacienda con PRIM tras el 68 (d. 8-X-68 h. 2-XII-70), supresor de aranceles e introductor de la peseta. Que CERDÁ y FIGUEROLA fueron amigos hasta muy tarde lo confirma aquél en su diario (cfr. Dia, 1875: 7 julio)

FIGUEROLA, a pesar de ir de compañero de candidatura progresista con MADOZ en las elecciones de 1858, fue un defensor a ultranza del librecambismo - frente al proteccionismo localista de MADOZ - y al llegar a ministro de Hacienda elevó la peseta catalana a moneda

\footnotetext{
${ }^{2}$ MAdOZ dimitiría por insidiosas insinuaciones del Conde de SAN LUIS, Ministro de Gobernación; cfr. PAREDES, 1982: 193-4 y 217, n. 115; MARGARIT, en CATÁLOGO Mostra Cerdà, 1994: 146

${ }^{3}$ Exactamente, según él mismo dice: »(...) Todas estas operaciones hechas con un escelente Teodolito de Troughton de $0^{m}, 165$ de diametro reunen cuantas condiciones de precision y ecsactitud pueden apetecerse " en un meticuloso informe suyo de 24 enero de 1855 (casi un mes y una semana después de haberlo iniciado) que eleva al Gobernador civil FRANQUET para que este pudiera justificarse ante los militares (AGMS: $3^{\mathrm{a}} / 3^{\mathrm{a}} / \mathrm{leg} .138, \mathrm{~B} \S 6 \mathrm{c} / 55$, Anexo $2^{\circ}$ del informe de FRANQUET al Mº de Guerra de 22-II-1855).
} 
nacional (1868) y redujo los aranceles para la importación textil, provocando la dimisión de MADOZ de presidente de la Comisión de Presupuestos en 1869 (cfr. PAREDES, 1982: 327 y 377 Ss).

\section{B) Científicos corógrafos y estadísticos}

$\S 8$. La actitud reverencial ante el cientifismo dominante era el paso necesario para poder entrar por derecho en el mundo de las Ciencias y, en concreto, de las ciencias sociales de la época (COMTE), en la que el uso de la estadística era imprescindible como fuente de información cuantitativa y mensurable, aunque no se supiera muy bien qué hacer con ella. La proliferación de diccionarios y enciclopedias del saber codificado es simplemente su expresión.

Había en ello un algo de patriotismo, de acercamiento al mejor conocimiento de su propia tierra y gentes, de descriptivismo corográfico de los geógrafos clásicos, con el adobo de unos datos estadísticos particulares. Como recoge un muy poco conocido diccionario español, el primero que, tras el de Madoz, intentará emular su senda ya en el siglo XX y precisamente bajo el franquismo, al iniciar su introducción con una sentencia de 'Azorín':

"La base del patriotismo es la geografía. No amaremos nuestro país, no le amaremos bien, si no lo conocemos" ('Azorín', 1916: Un pueblecito; cit. en DICCIONARIO GEOGRÁFICO DE ESPAÑA, 1956-61: LXVII).

La preocupación por hacer ciencia con la información cuantitativa disponible para ponerla a disposición de los políticos que hubieran de tomar decisiones y para la información del conocimiento específico y preciso, fue el vehículo para delimitar los campos disciplinares de muchas ciencias incipientes, lo que permitía centrarlas en el objeto preciso de su propia disciplina. MADOZ es un prototipo de los ilustrados del XIX que aportan al conocimiento, no sólo el ideario (las ideologías iluminadas, el Erklärung, la claridad luminosa...) del Siglo de las Luces, sino los datos, la ciencia, los medios para ponerla a marchar de manera eficaz y consistente: la Estadística, la entonces llamada Ciencia de la Estadística (casi todo lo que era serio y podía usar las matemáticas quería ser Ciencia, aunque no fuera tal, para diferenciarse de la Filosofía y las Artes, ya que no afinaban entre ciencias básicas, aplicadas o técnicas de producción y acción) fue el gran asidero de estas disciplinas aplicadas. Su método consistía en la recopilación de toda la información relacionada con cualquier tema llevada ad libitum, hasta el despliegue informativo exhaustivo de todos los datos disponibles, muchas veces sin saber muy bien con referencia a qué disciplina, pero eran datos que se suministraban para que alguna vez pudieran ser utilizados sin saber cuándo, ni por quién, ni para qué.

Los diccionarios que se propusieron en aquellos años cruciales de finales del siglo XVIII, como el de la Academia de la Historia, y del inicio del XIX, como el de Sebastián MiÑANO (182629) y el voluminoso Diccionario Geográfico-estadístico-histórico... de MADOZ (lo inicia en 18345 ), así como los ejemplos del extranjero que pueden traerse (el propio MADOz conoció el ALCEDO, ECHARD, etc.), encierran datos y datos que se recopilan, amontonan y lanzan ordenados por criterios no espaciales ni históricos, sino alfabéticos, que se suministran ex abundantia cordis como muestra de una facultad ilimitada de obtener informaciones para todo tipo de conocimientos. El propio MADOZ dice haber reunido materiales por sus más de mil informadores corresponsales "para más de cien volúmenes, materiales que yo no podré utilizar..." pero de los que dará una copia al Gobierno... que nadie sabe donde han ido a parar (cfr. QuIRÓs \& al., 2005). 
MADOZ, precisamente mientras estaba preparando la edición de su propio Diccionario, fue Presidente de la Comisión de Estadística del Gobierno moderado con ESPARTERO, regente, y el primer Gobierno NARVÁEZ con ISABEL II (21-8-1843 / 8-2-44)

§9. Fue la Estadística también una obsesión cientifista del CERDÁ contemporáneo de MADOz. La 'Introducción' al Diccionario de MADOZ (cfr. MORALES \& al., 2005: 123-150) es una buena muestra de las virtudes taumatúrgicas que por sí sola se le daba en aquellos años (vide ibidem: 129-142, §§16-40, la sabrosa introducción a la historia comparada de la estadística que escribe MADOZ). Las palabras de CERDÁ sobre esta misma concepción de la estadística merecen ser recordadas y airosamente comparadas con las de MADOZ, ya que se plantea uno de los principios del método científico, el paso de la inferencia deductiva de datos comprobados hacia la inferencia inductiva de la construcción teórica (cfr. GARCíA-BELLIDO, 2000); sólo que en este caso procediendo al revés, aportando hechos individuales que confirmen la validez genérica de la teoría:

"Ahora bien, aquella abstracción cuidadosamente generalizada en el examen de la urbe [referente al tomo I de la TGU, teórico y universal], y esta casi omisión del estudio del vecindario, forman una tarea harto incompleta, poco adecuada para establecer hechos ciertos, fijos y genuinos, sobre todo de esos que llevan instantáneamente la convicción al ánimo del lector. Preciso es por lo tanto, antes de intentar siquiera sentar las bases de una teoría urbana [cosa que acababa de hacer en el t. I de la TGU], acometer un estudio especial, concreto, individual, si así cabe decirlo, de una urbe determinada, y poner además su parte material en parangón con el vecindario que contiene, y procurar por este medio comprender las relaciones íntimas, indisolubles, que entre el continente y su contenido existen, á fin de juzgar con pleno conocimiento de causa si en esas correlaciones hay justa correspondencia, equidad y armonía, ó bien inícuas preponderancias, desequilibrio y desconcierto" (CERDÁ, 1867: TGU, II: 2; cvas mías)

O sea, usar los datos reales y compararlos con estándares éticos a priori, no había otra cosa; o a lo sumo con otras ciudades concretas para juzgar su situación particular mediante el método comparativo-analógico, científicamente muy escurridizo. Y, colocando a la Estadística en su lugar meramente instrumental para alcanzar el objetivo del estudio y conocimiento de un lugar o hecho concretos, aunque con la veneración implícita de los números y guarismos con los que siempre ha seducido la Matemática, en especial para las ciencias sociales de aplicación práctica (pensando en la 'urbanización' o Urbanística, evidentemente al hablar de la 'estadística urbana' como fundamento de aquélla), CERDÁ añade:

"Para llegar á ese apetecido objeto, he creído lo mas conducente apelar á la estadística, á ese arsenal inagotable de razones contundentes é irresistibles, á que han acudido con feliz éxito todas las ciencias sociales de aplicación práctica. Después de una serie de operaciones, problemas y resoluciones abstractas, bueno será y muy conducente dar valores absolutos y concretos á todos los términos del raciocinio, reproduciendo iguales operaciones en forma aritmética y con guarismos. De esta manera no valdrá decir que puede haber tenido parte en las apreciaciones el capricho de la imaginación; sino que será preciso reconocer que son hijas de la lógica irreprochable de los números." (ibidem: 2-3; cvas mías)

Reafirmando la relación guarismos-teoría con: 
“...porque no teníamos más objeto que reunir y esponer por un sistema de tablas pitagóricas ó cuadros sinópticos, convenientemente ordenados y enlazados, todos los datos aritméticos que han de servirnos mas adelante para escribir la filosofia de la estadística urbana, sobre la cual hemos de fundar la teoría de la urbanizacion" (ibidem: 677; cvas. mías) [piénsese que Cerdá anuncia en el epílogo final del segundo tomo de la TGU que iba a escribir un tercer tomo para "penetrar en el vasto campo de las árduas especulaciones teóricas, á fin de sentar los cimientos de la ciencia y del tecnicismo, que deberían en nuestro concepto servir de norma y guia á los futuros proyectos y trabajos que para fundar nuevas urbes ó reformar y mejorar las existentes, en adelante hayan de acometerse" (ibidem: 700)]

\section{C) Empresarios inmobiliarios}

$\S 10$. Respecto a las incursiones empresariales de MADOz con "La Peninsular" tan sólo decir que constituye su mayor aportación como empresario - superando con mucho en riesgo y ventura a su primera empresa cultural editorial-impresora del Diccionario-, llegando a consolidar "en la práctica una de las más poderosas empresas inmobiliarias: la primera empresa constructora a gran escala del siglo XIX" (BAHAMONDE, 1992: 381).

La posición espacial de casi todas sus intervenciones inmobiliarias entre 1862 y la crisis del 1866-69 muestran cómo en aquellos años la renovación urbana en los solares intramuros ofrecidos por la desamortización $\left({ }^{4}\right)$ eran los únicos y más rentables, con fuerte subida de precios en esos años, precisamente por ser los últimos disponibles antes de empezar a gestionarse y urbanizarse el ensanche de CASTRO, por entonces en un limbo de dudosa vigencia (ver MAS, 1999; FRECHILLA, 1999).

$\S 11$. No deja de ser relevante que MADOz estuviera en 1856 en el "Consejo de Vigilancia" (proto-espécimen de los actuales Consejos de Administración, formado por prohombres de renombre y poderosas influencias en las finanzas, la política y la aristocracia) de la sociedad inmobiliaria 'La Tutelar', fundada por R.O. de 23 ag. 1850 y reformada el 10 jun. 1857 (con 70.000 imponentes y 500 millones de rs en 1860), cuyo director era Pedro PASCUAL DE UHAGóN y que MADOZ dejaría en 1860 para fundar su 'La Peninsular' (cfr. PAREDES, 1982: 352; BAHAMONDE \& alii, 1978: 26-7; BAHAMONDE, 1992).

El interés radica en que UHAGÓN y CERDÁ fueron no sólo amigos, sino decididos impulsores de las primeras operaciones reparcelatorias de propietarios del Ensanche de Madrid que el propio UHAGÓN había propuesto en una hoja suelta volante con el título de Dos palabras á los propietarios de terrenos comprendidos en la zona de ensanche de Madrid, en la que reclamaba salieran las normas y ordenanzas para la aplicación y desarrollo del Ante-proyecto del plano del Ensanche de CASTRO, recién aprobado precipitadamente por R.D. de 19 de julio de 1860, y proponiendo que los propietarios se asociasen para "el apresto del terreno" y autofinanciasen las obras. La coincidencia con las propuestas que CERDÁ había preparado ya para el Ensanche de Barcelona en el "Pensamiento económico" (expuesto al Ministro de Fomento, Marqués DE CORVERA, el 23 de enero de 1860), debieron impulsarle a éste a escribir otro folleto con fecha 29 de noviembre de 1861 titulado Cuatro palabras más sobre las dos palabras que Don Pedro Pascual de Uhagón ha dirigido á los propietarios de los terrenos

\footnotetext{
${ }^{4}$ El mejor trabajo informativo y gráfico, con los planos comparativos detallados de las piezas urbanas desamortizadas y el uso dado a cada una con sus transformaciones inmobiliarias posteriores, puede verse en el trabajo histórico geográfico de PINTO \& MADRAZO (2001, vol. II: 49-52).
}

ACE, Vol.1, núm. 1, pp.4-28, 2006 | PASCUAL MADOZ E ILDEFONSO CERDA, DOS PIONEROS EN LA EPIFANIA DE LA URBANISTICA 
comprendidos en la zona de ensanche de Madrid (CERDÁ, 1860, CPM), argumentando y dando detalles de cómo podía montarse económica y financieramente la operación que UHAGÓN sólo esbozaba en su hoja volante $\left({ }^{5}\right)$. CERDÁ aprovecha para impulsar la idea de la inseparable unidad del ensanche (que estaba haciendo CASTRO) con el proyecto de la reforma interior de Madrid, que el ministro Marqués de CORVERA acababa de autorizarle a CERDÁ, por R.O. de 16 de febrero de 1860, y que en su cumplimiento engendraría su crucial obra Teoría de la Viabilidad Urbana de Madrid (TVU), fechada en enero de 1861.

Esta relación de apoyos técnicos y ánimos entre CERDÁ y UHAGón en favor de una gestión urbanística directa entre los propietarios - que fuese autónoma de la intervención expropiatoria municipal, lenta e incierta- será el vehículo de la introducción de la reparcelación cerdiana también en Madrid, por lo que habría que seguir las vinculaciones entre las inmobiliarias de MADOZ y UHAGÓN O, al menos, sus relaciones personales.

Por su parte, sabemos que CERDÁ fue también —en paralelo con MADOZ, si bien no como presidente capitalista- el Director facultativo o técnico de la sociedad inmobiliaria Fomento del Ensanche de Barcelona, entre junio de 1863 y mayo del 65, cuyo Secretario general era Manuel ANGELÓN y que dependía del capital de la razón social PUIG, VIDAL, BABOT y Cía (cfr. EstAPÉ, 1971; en CERDÁ, 1859: TCC, F.E.B.: 591-600)

\section{Al derribar las murallas de Barcelona se abre la oportunidad histórica para el nuevo urbanismo de expansión ilimitada.}

$\S 12$. El intenso proceso del derribo de las murallas de Barcelona, iniciado mucho antes de 1854, tiene trascendental relieve posterior por varios motivos encadenados que van a fundirse con el nacimiento del urbanismo en España. Su fundamento histórico universal reside en que el derribo de las murallas en general constituye el más decisivo acontecimiento de trascendencia territorial del Viejo Mundo entero, que entra en resonancia en todos los países casi a la vez, como el punto de inflexión e inicio del fin de una larga era de varios miles de años de urbanismo constreñido por las ciudades sucesivamente amuralladas.

Con el derribo de los recintos y cercas amuralladas se marca el origen preciso de la enorme explosión que desbordará la ciudad antigua, como en un Big-Bang cósmico, en múltiples grandes deflagraciones que han dado inicio a las megalópolis, a las conurbaciones de macrociudades-región, a la pantópolis en red global que ahora vivimos, que desborda continentes y se expande por un espacio-tiempo virtual informacional, sin saber ya cómo controlarla...

La ciudad clásica ha estallado y sigue expandiéndose con aceleración creciente, como ocurre en el cosmos termodinámicamente inflacionario. $Y$ en este acto histórico demoledor concreto de Barcelona, además convergieron múltiples actores protagonistas y fenómenos político-sociales de gran trascendencia posterior que catalizarían el despegue de la autonomía municipal y con ella del urbanismo.

§13. En varios trabajos anteriores se ha descrito con sobrada información y detalle todas las incidencias hasta el logro de la ansiada demolición de las murallas (vide per alia ESTAPÉ, 1971; Grau \& LóPez Guallar, coords., 1988, caps. IV, V y Vl; Nicolau \& Cubeles, 2004; SagarRA,

\footnotetext{
${ }^{5}$ El mismo CERDÁ había escrito un opúsculo seis meses antes con parecido título de "Cuatro palabras sobre el Ensanche, dirigidas al publico de Barcelona" un 12 de mayo de 1861, que es una elaboración de la "mancomunidad de reparto' en asociación de propietarios que venía proponiendo y que Posada HERRERA (Ministro de Fomento interino un mes, entre 21 nov. y 18 dic. de 1861) plasmaría en su proyecto de ley no-nato de aquel mismo mes de diciembre de 1861.
} 
2004; etc.). Y, más en concreto, el relevante papel que jugaron en ello, tanto el propio General Domingo DULCE (segundo hombre de la 'Vicalvarada' de julio de 1854 y mano derecha del General ESPARTERO, Duque de la Victoria), que fue Gobernador militar de la plaza, hasta que llega el mismo MADOZ a su puesto de Gobernador civil de Barcelona, desde donde sería el definitivo impulsor de su arrasamiento y autofinanciación, se han detallado y contextualizado gracias a la reciente documentación hallada en archivos militares ponderando el papel crucial de MADOZ en estos sucesos (GARCíA-BELLIDO, 2005b; GARCíA-BELLIDO \& MANGIAGALLI, 2006).

La importancia de lo que ocurrió en aquel verano y otoño de 1854 se pone de relieve si se sintetizan los seis procesos revolucionarios que se concitaron en aquel momento y cuya expresión y convergencia en este punto marcan la verdadera dimensión histórica del tiempo y del lugar que nos ocupan:

(i) se inicia el derribo generalizado de las murallas de casi todas las ciudades españolas y europeas (el espacio extramuros se funde con el intramuros: con la demolición de las barreras se hace isótropo el crecimiento urbano en todas direcciones, nacen formalmente los ensanches de poblaciones y acaban siendo desbordados en una formidable explosión de las megalópolis);

(ii) se entabla una dura tensión jurisdiccional-competencial entre el poder civil y el militar (expresada en lo político en los continuos 'movimientos', pronunciamientos y asonadas golpistas del XIX y XX), en este caso centrada en la transición del otrora pleno control del Ministerio de la Guerra del espacio jurisdiccional militar de sus zonas polémicas en torno a las plazas fuertes o 'plazas de guerra' que, al perder relevancia los sistemas defensivos de fortalezas ante las nuevas armas destructivas, van a desguarnecerse las ciudades-fortaleza medievales, pasando la competencia espacial de su control al poder civil de los ministerios de Gobernación o de Fomento, ante la arrolladora dispersión urbana que empieza a desbordar las ciudades.

(iii) estalla una epidemia de cólera arrasadora (desencadenante del higienismo urbano, como ya estaba ocurriendo desde diez años antes en otros países, lo que incitaría el Estado asistencial en su vertiente de viviendas sociales hasta ahora);

(iv) se produce la primera huelga general de una entera comarca laboral de Europa (la de Barcelona de julio de 1855) debido al estallido social provocado por el paro que está arrastrando la imparable revolución industrial (politización y reacción obrera frente a su explotación: socialismo revolucionario);

(v) se vislumbra el lento inicio de la autonomía financiera y la capacidad de endeudamiento de los ayuntamientos para resolver sus propios problemas sin depender de la caridad del centralismo estatal (municipalismo y nacionalismo fueron unidos);

(vi) mientras llega, se ingenia por primera vez una fórmula que cierra el anterior círculo abierto basando la financiación de las obras públicas en los beneficios privados que engendra el urbanismo municipal, con cuya capacidad de endeudamiento con cargo al gasto público se pueden derribar las murallas, paliando así el problema del paro-hambre inicial (urbanismo-gestión pública-plusvalías privadas) e iniciando el simbólico slogan desarrollista de que "el urbanismo-edificación es el motor del crecimiento de la economía", cuya potencia es cebada con la urbanización creciente del territorio, premisa de la acumulación de la circulación primitiva de capital, que sigue idéntica hasta hoy día...)

$\S 14$. Y en esta formidable coyuntura histórica se cruzan dos personajes que van a servir de catalizadores de aquellas condiciones socio-económicas objetivas para impulsar en una dirección progresista el proceso revolucionario del urbanismo español y, en gran parte europeo: MADOZ Y CERDÁ. 
MADOZ es el político activo en el momento oportuno: era a la sazón el gobernador civil y al preocuparse en su progresismo liberal por el paro y el deseo de desarrollo industrial, se erige en impulsor del derribo combinándolo con el recurso suelo estatal y capitales privados para emplear a los obreros despedidos por las selfactinas en una conjunción inteligente de recursos y objetivos, en un lúcido approach prekeynesiano, diríamos ahora, al conjuntar tres problemas, paro-desarrollo-crecimiento, en una misma operación de inversión público-privada y empleo, cuyos plusvalores crean más capital e inversión, etc.

Y CERDÁ era por entonces un maduro Ingeniero de Caminos de 39 años, que estaba proyectando y construyendo carreteras y ferrocarriles por toda Cataluña y que desde $1844-$ nos dice él- ya le había arrebatado el interés por la 'construcción de las ciudades', quedando situado por estas circunstancias históricas en el centro de un huracán político que demanda una potente y novedosa solución técnica. La pregunta que sólo un proyectista intrigado ante aquel paso gigantesco de demoler las murallas podría formularse: “... y tras derribar esas murallas, ¿cómo desplegamos, que forma le damos, cómo gestionamos una nueva ciudad en tan generoso espacio abierto?". El reto que él se formula a sí mismo ante su inquieta mirada esa es su genialidad - se lo plantea como pregunta crítica frente a los muchos problemas higiénicos, económico-financieros, administrativos, municipales, sociales, de vivienda de la población que no se habían planteado nadie nunca antes, de ahí su originalidad científica revolucionaria $\left({ }^{6}\right)$.

Situación y encrucijada política que CERDÁ sabrá aprovechar técnicamente (formará parte de una Comisión de expertos ad hoc y precipitadamente mientras se derribaban las murallas de tierra se le encargará levantar la cartografía detallada del entorno del territorio de la ciudad) para lanzar su potencia creadora hacia la concreción efectiva de esa nueva disciplina que se le abría ante su amplia e inquisitiva mirada con el derribo de las murallas y su apertura ilimitada sobre el llano de Barcelona.

La apertura explosiva e isotrópica de la ciudad será precisamente lo que percibirá CERDÁ como signo de los tiempos de la locomoción expansiva, en aquella red infinita y jerarquizada de vías e intervías en malla ilimitada, colocándole en una absoluta posición precursora, muy por delante de todos los urbanistas europeos de su época (cfr. TARRAGÓ, 1992; MAGRINYA, 2003).

Véase cómo se entrelazaron los hechos biográficos de estos dos 'sujetos inductores' de 'hechos históricos' trascendentes: es como asistir al alumbramiento de una tierna disciplina socio-política y ver cómo apuntan sus rasgos esenciales que se desplegarán con su desarrollo futuro determinando el urbanismo español del siglo y medio siguiente y -me atrevo a afirmarrepresentando el revolucionario inicio del urbanismo mundial de los dos siglos siguientes.

\subsection{Una demolición anunciada.}

$\S 15$. Es sobradamente conocido cómo desde los primeros planteamientos oficiales municipales de 1838-39 solicitando "alguna expansión urbana" de la ciudad (con respuestas de tímidas ampliaciones parciales de los militares), hasta la convocatoria en 1840 del concurso municipal sobre el derribo de las murallas y el famoso artículo ganador - fue el único presentado- del médico higienista Pedro Felipe MONLAU, con el título de iiiAbajo las murallas!!! Memoria acerca de las ventajas que reportaría á Barcelona y especialmente á su industria de la demolición de

\footnotetext{
${ }^{6}$ Piénsese que hasta entonces o se hacían sucesivos recintos parciales crecientes con los arrabaes de las ciudades para volver a amurallarlos en torno al perímetro anterior o se hacían reformas puntuales de plazas o lineales de calles y avenidas, como hicieran Les Artistes, NAPOLEÓN III y HAUSSMANN en París, o se replanteaba una ciudad o nueva población enteramente ex-novo para la colonización agraria o en las regiones coloniales, por lo que la percepción de un espacio en torno a la ciudad infinitamente creciente antes no se había planteado jamás. Lo mismo ocurriría con los Stadt-Erweiterungen alemanes coetáneos.
} 
las murallas que circuyen la ciudad (Barcelona, sept. $1841 ; 21$ pp.) —en el que ya demanda la expansión de río a río-, el clamor de la ciudad para dejar de ser plaza fuerte militar y poder sacar las industrias y talleres que agobiaban su reducido cerco, estaba convirtiéndose en un grito catalanista símbolo de su misma libertad civil.

Las quejas no eran sólo por el hecho físico de desembarazarse de las murallas y del sofocante espacio vacío de las 'zonas de tiro' de un cuarto de legua de radio de la 'zona polémica o táctica' que envolvía el extramuros de toda fortaleza o ciudad considerada plaza fuerte $\left(^{7}\right)$, sino por el hecho de acabar con la amenaza que confería a la misma población un estatus de permanente objetivo militar para la represión interna, como potencialmente revoltosa, situación arrastrada desde la Guerra de Sucesión y la dura reacción borbónica que la mantenía bajo un vigilante control militar (cfr. MAS, 2003: 145-165).

Las demandas para el desahogo de las murallas que agobiaban el desarrollo industrial de la ciudad, y los intentos y 'bullangas' para demoler unos cuantos lienzos en cuanto se presentaba la oportunidad, fueron una granizada constante, desde los encendidos artículos de Jaime BALMES en 1843, el extenso informe municipal que es remitido a Madrid el 24 de mayo de 1853, hasta la solicitud de los Diputados catalanes de todos los partidos de 18 de diciembre de 1853 (encabezada por MADOZ), sin dejar de presionar por todos los medios para el derribo de las murallas, cuya competencia era del Ministerio de la Guerra... hasta el 17 de agosto de 1854 en que se dio el definitivo paso para legalizar su derribo irreversible, justamente cuando, con la Revolución de julio de 1854 del 'Bienio progresista', MADOZ acababa de llegar de Gobernador civil a Barcelona.

Estos procesos vitales para una ciudad, que, como un crustáceo, necesita romper y abandonar su estrecha coraza que le aprisiona para poder crecer, han sido meticulosamente estudiados y descritos reiteradas veces, al ser el elemento definitorio de una gran inflexión en la historia de una ciudad (cfr. ESTAPÉ, 1971: 115-152; BENET \& MARTí. 1976; per alia vide GRAU \& LóPEZ GUALLAR, coords., 1988: 150-163; en especial, GIMENO, 1994; NiCOLAU \& CUBELES, 2004).

\$16 Fue, en aquellos días de enero del 54, cuando el diputado a Cortes, Sol I PADRIS, amigo de MADOZ $\left({ }^{8}\right)$, propuso la formación de una comisión de ingenieros y arquitectos encargada de levantar el plano topográfico de la zona de Ensanche. Sea por aquella propuesta o fuere por la evidencia de su necesidad técnica, el hecho es que se constituyó una importante Comisión mixta civil y militar al final del año, ya en el Bienio progresista (y que citará CERDÁ en su DiarioÍndice Cronológico, ICr de 19-I-54), creada por la importante Real Orden de 26 de octubre de 1854 del Ministro de la Guerra, ya que aquellos eran los 'dominios competenciales' del ramo militar (cfr. ESTAPÉ, 1971: 144).

Esta permanente tensión en aquellos años cruciales estallaría entre el poder de la Milicia, que veía en peligro su preponderante papel de controladora exclusiva del espacio periurbano amurallado por principios de seguridad de su defensa, y el poder político civil que, desde los dos niveles estatal (ministerios de Gobernación o desde el 1855 por Fomento) y

\footnotetext{
${ }^{7}$ La 'zona polémica' rodea las murallas de toda fortaleza murada en un radio de $1.254 \mathrm{~m}$ o 1.500 varas castellanas, desde que lo estableciera el art $^{\circ} 10$, tit. II, Tratado VI de las Ordenanzas militares de SM para el regimen, disciplina, subordinación y servicio de los ejércitos... de 12-agosto-1790; ver tb. CERDÁ, 1859 (TCC: 258, §510). En italiano esta zona se llamaba spianata, 'explanada' en torno a la cinta murata, extra-moenia.

${ }^{8}$ SOL Y PADRís, patrono fabricante y presidente del Instituto industrial, fue muy activo en estos años, formando parte por designación directa de MADOZ de la Comisión de la Junta del empréstito formada desde octubre 1854 para financiar las obras. Sería asesinado de un pistoletazo el 2 de julio de 1855, en un choque en la barriada de Sants, en la fábrica de Güell y Ramis (cfr. TUÑ́́N, 1960: 156; BENET \& al., 1976: II: 11-15), en la explosión de la huelga general de Barcelona atizada por el expeditivo general Juan ZAPATERO y sus incendiarios bandos (apodado como el general 'Cuatro tiros', 'el tigre de Cataluña', el 'Verdugo de los catalanes' y el 'Bajá de Cataluña'; BENET \& MARTí. 1976: I: 756).
} 
municipal, reclamaría esa jurisdicción territorial en todos los ensanches de poblaciones por criterios exclusivamente funcionales de gobierno del territorio municipal y de policía urbana.

$\S 17$. Las coordenadas del problema hay que situarlas, pues, en un encadenado de conflictos de las tres partes en juego con intereses legítimos sobre la misma cuestión, a saber: por parte del Estado estaban el ministerio de la Guerra y el de Gobernación civil (aunque Gobernación se inclinaba más por los intereses locales) y por la parte local el Municipio personificado en el Ayuntamiento; ante cuyo triángulo se planteaban a su vez tres grandes temas cuyo cruce de opciones fue siempre polémico:

(a) demolición o no de las murallas: si es que sí, depende de si Barcelona va a seguir siendo plaza fuerte (en cuyo caso hay que rehacerlas un poco más lejos) o ya no más (en cuyo caso puede ser "ciudad ilimitada")

(b) financiación de las obras de su demolición: bien con cargo al reciclado y venta de las piedras del derribo (que no llegaba a cubrir gastos de la demolición) o/y bien con cargo al suelo público que puede ser: tanto para usos públicos no lucrativos (ronda, bulevares, edificios institucionales), como privados muy lucrativos; lo cual va a depender de quién o para quien sea el...

(c) dominio del suelo liberado y del vuelo futuro: bien sea el suelo del Estado, del Municipio o de los particulares (incluido el Patrimonio Real de Isabel II, que reivindicará el suelo de las murallas como patrimonial privado suyo); bien sea el vuelo potencial y las plusvalías del mismo, porque el saber si el valor real de los solares excluye las plusvalías futuras o las incluye como valor potencial futuro de los mismos, sean de quien sean, es la base del precio en las subastas públicas, lo cual va a ser clave para quien resulte ser el propietario de los terrenos y, por el derecho de accesión, de su vuelo edificable.

En este último punto sutil y escurridizo — que aún sigue siendo el centro del debate en todo el urbanismo mundial y, con mucho, aun vivo en nuestro país - se van a reordenar las demandas y polémicas que explican todo el farragoso asunto de las murallas, y no solo de Barcelona. Y precisamente en este punto va a centrarse la irrupción económico-financiera del MADOZ Gobernador civil al levantar un empréstito para financiar las obras del derribo, resguardándolo en ese escurridizo y polémico valor futuro que alcanzarán los solares de las murallas; lo que, por ende, le hará penetrar en los problemas del urbanismo con su amigo CERDÁ y su interés por los temas inmobiliarios al final de su vida.

$\S 18$. No eran nuevas ciertamente estas preocupaciones e intereses encontrados en la apropiación de las rentas del suelo. De hecho cabe pensar que en todos los procesos antiguos de demolición de un recinto y recreación de nuevas murallas ampliando su protección a los burgos y collationes extramuros, debió financiarse de modo análogo. Ya habían aparecido por entonces (1843-44) las primeras propuestas, con los precarios medios municipalistas disponibles, para afrontar el tema central y universal en todos los urbanismos en la Historia: ¿cómo gestionar y financiar las costosas obras que requieren las ciudades y quién debe pagarlas, según quién sea y en qué medida quienes vayan a internalizar sus beneficios?

Por eso nos interesa este episodio histórico, en tanto que es cabecera de un hilo del enrevesado ovillo, cuyo desciframiento nos permita alumbrar los orígenes de la formación de algunas instituciones clave para la gestión de la urbanística universal: la Historia no como objeto en sí misma de los hechos y datos casuísticos que alberga, sino como medio para el conocimiento de los procesos sociales de cuyo análisis se puedan extraer la síntesis de presuntas leyes tendencialmente universales que puedan explicar hechos análogos allá donde ocurran (cfr. GARCÍA-BELLIDO, 2005a) 


\subsection{La plusvalía urbanística de las murallas creadora de empleo para paliar el paro generado por la revolución industrial.}

§19. Vuélvase al inicio del Bienio progresista, en julio de 1854, con el triunfo de O'DonNELL y el general Domingo DULCE, nombrado Gobernador militar de Barcelona desde el 10 de agosto (en sustitución del general DE LA ROCHA), encontrándose con que la Junta Provisional revolucionaria de Barcelona, el 5 de agosto por su cuenta, alienta a los barceloneses a derribar las murallas de tierra (las del lado del mar serían mantenidas hasta 1858), siendo nombrado MADOZ Gobernador civil el 8 de agosto y llegando a Barcelona el 11 de agosto.

La primera labor de DULCE fue conseguir sacar de Madrid una Real Orden comunicada de 12 de agosto del Gobierno de ESPARTERO, trasladada el 15 al Ayuntamiento, con la que se 'legalizaba' el derribo ya realizado y lo decretado unilateralmente por la Junta Provisional la semana anterior, reservándose el Gobierno dos cuestiones:

(i) la de "resolver el destino que debe darse à los fondos que produzca la venta de los terrenos y de los materiales, pero que los gastos que produzca el derribo, debe desde luego, costearse de estos mismos"; la cual el Ministerio transmitirá al Capitán General como: "Se pondrán en venta los terrenos sobre los cuales se hallan las fortificaciones, y su producto, asi como el que proporcione la enajenacion de los materiales, tendrán legal y oportuna aplicación, sirviendo desde luego, en la parte necesaria, para sufragar el coste del derribo"; y

(ii) "la cuestión de si Barcelona ha de ser plaza de guerra y cómo debe fortificarse si así se

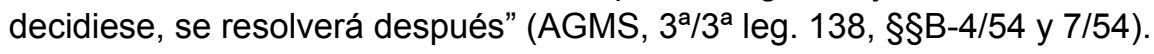

La condición legal de plaza fuerte, que subsistiría hasta 1858 , es la más pesada servidumbre sobre los propietarios del llano, porque seguía bloqueando toda la 'zona polémica' de 1.500 varas castellanas (1,2 km.) del ensanche en derredor (CERDÁ: ICr; TUÑón, 1973: 1547; BENET \& MARTí, 1976: I: 463-7; GIMENO, 1994). Esta previsión de que los terrenos de las fortificaciones "se pondrán en venta" como propiedad patrimonial del Estado, al objeto de pagar con su producto los costes del derribo, además de otros fines que se deriven de su "legal y oportuna aplicación" (mejoras en las instalaciones defensivas), constituye un recursivo recurso económico-financiero que es muy posible que la Hacienda Real y militar hubiera venido aplicando en los procesos de derribo, por desbordamiento y ampliación de su perímetro -al querer abrigar a los burgos y collationes asentados extramuros con nuevos recintos amurallados- que, desde la Edad Media, hayan podido realizarse (cfr. De SETA \& LE GoFF, eds., 1989). Recurso financiero que el MADOZ gobernador convertiría en ventaja económica de primer orden dos meses después, pero del Municipio, haciendo pasar los frutos de ese recurso inesperado del patrimonio del Estado y de Guerra — que además debía ser expresamente controlado por "la organización del Cuerpo de Ingenieros (técnicos) y la Administración Militar (juristas y gestores) en la parte que respectivamente les compete, según sus atribuciones", pero sin darle vela de esa competencia, en absoluto, al municipio- al patrimonio municipal o, al menos, a la capacidad de gestión municipal directa de los beneficios del mismo, al hipotecar los bienes patrimoniales del Estado para respaldar las inversiones privadas de capital que le valdrían al Municipio para pagar sus deudas.

$\S 20$. En efecto. El 21 de septiembre de 1854 el Ayuntamiento eleva una nueva petición a ISABEL II en la que expresa el agotamiento de sus recursos económicos en plena epidemia de cólera y la imposibilidad de conseguir otros fondos que permitiesen continuar las obras de demolición, pidiendo al Estado que cubra los gastos realizados hasta ahora por el Ayuntamiento y los que

ACE, Vol.1, núm. 1, pp.4-28, 2006 | PASCUAL MADOZ E ILDEFONSO CERDA, DOS PIONEROS EN LA EPIFANIA DE LA URBANISTICA 
se hicieran en el futuro, "si el propietario de los terrenos del glacis iba a ser" el Ministerio de la Guerra (cfr. PAREDES, 1982: 248).

Cuando Madoz preparaba su marcha de Barcelona, reclamado por su partido para asumir tareas en el Congreso y en el Gobierno central donde se necesitaban sus servicios, entre el 1 de octubre y el 8 hace un viaje a Madrid (a votar en las elecciones generales a Cortes constituyentes) y consigue 'arrebatar' del Ministro de Hacienda, su correligionario (y no sabía que tan bien sería su predecesor) José Manuel ColLAdo PARADA (30-VII / 28-XII-54), la trascendental R.O. comunicada de 6 de octubre, donde se apoyan económicamente las aspiraciones barcelonesas; y ello sin decirle nada al general O'DONELL, Ministro de Guerra a la sazón (30-VII54 / 11-X-56). Su texto no puede ser más expresivo y excepcional autorizándole como Gobernador civil a emitir un empréstito garantizado con una hipoteca sobre los terrenos de las murallas para obtener la liquidez suficiente, no sólo para pagar las deudas ya contraídas con los gastos del derribo, sino para seguir pagando a los obreros empleados en paro por las selfactinas hasta el final de las demoliciones:

»Excm ${ }^{\circ} \mathrm{Sr} . \approx \mathrm{He}$ dado cuenta á la Reina (q.D.g.) de la comunicación que dirijió V.E. á este Ministerio [de Hacienda] en 17 de Setiembre ultimo [texto no hallado aún], haciendo presente el lamentable estado de esa Ciudad y proponiendo como medio de atender al sostenimiento de la tranquilidad pública y al socorro de las demas necesidades de la poblacion que se le autorizase para levantar un emprestito con la hipoteca especial de los terrenos de las murallas y sus glacis. Tambien he enterado a S.M. de una esposicion que viene á enlazar con el espresado asunto, y en la cual el Ayuntamiento Constitucional de esa Capital solicita que se abonen por cuenta del Estado las cantidades invertidas yá y las que se inviertan en adelante en el derribo de las murallas de la misma.

En su virtud y teniendo presentes las razones espuestas en apoyo de ambos objetos, y las manifestaciones vervales [sic] que para su mayor ilustracion hizo V.E. en el dia de ayer [5 de oct.], S.M. con Ministros se ha servido autorizar á V.E [al mismo Gobernador civil]:

$1^{\circ}$ para levantar el citado emprestito por la cantidad mayor posible al interes mas beneficioso que pueda obtener hipotecando á su reintegro como garantía los terrenos que resulten de la demolicion de las murallas y sus glacis en la parte indispensable á cubrir la cuantia del prestamo.

$2^{\circ}$ para destinar de su importe la suma de tres á cuatro millones de reales a reintegrar en virtud de cuenta justificada las cantidades invertidas por el Ayuntamiento en la espresada demolicion prescindiendo, por justa deferencia á aquella corporacion que tantos servicios ha prestado al orden á la libertad y á la humanidad, de la manera y de la clase de operarios con que ha tenido necesidad de ejecutar dicha operación; y

$3^{\circ}$ para continuar esta en adelante en la forma que V.E. estime mas conveniente y economica; aplicando el resto de la cantidad fijada anteriormente á satisfacer los gastos que ocasione por cuenta del Estado, puesto que las murallas y los terrenos que de su derribo resulten son propiedad de la nacion, á pesar de cualquiera opinion que acerca de este punto se quisiese indicar en contrario [en referencia evidente a las reivindicaciones municipales sobre la propiedad de los terrenos].

De Real Orden lo digo á V.E. para su inteligencia y efectos oportunos. Dios que á V.E. m. a. Madrid, 6 de Octubre de $1854=$ José Manuel Collado PARADA = Sr. [MADOZ] Gobernador de la provincia de Barcelona.» (AGMS, 3a/3a/leg. 138; §B-10/54; Diario de Barcelona, 19-X-54, $\mathrm{n}^{\circ}$ 291: 7.298-9) 
Su apoyo político circunstanciado le vino en que con esa fórmula podía resolver tres cosas más: el abono de los costes de demolición de las murallas, el emplear a la mano de obra local sacándola del paro de la crisis de las selfactinas, y tratar de enjugar el galopante déficit económico municipal, acelerado con motivo de la epidemia del cólera.

$\S 21$. En desarrollo de la anterior R.O. de 6 de octubre MADOZ elabora un proyecto de empréstito que será clave en el entendimiento del urbanismo español y que parece había presentado ya el 17 de septiembre $\left({ }^{9}\right)$. Esta autorización para emitir un empréstito es un documento de sumo interés histórico-urbanístico por ser el primero -hasta ahora, que sepamos- en recogerse en él una línea jurídico-financiera garantista de rentas futuras privadas respaldadas por el Estado, que se iniciaría desde entonces hasta nuestros días de modo creciente, en vez de rechazar esa línea virtual potencial o expectante, contraria a la economía positiva y real, como hicieron otros países...

MADOZ le dio curso y abrió el 18 de octubre la suscripción de cédulas al portador para cubrir este empréstito de 20 millones de reales de vellón [como es sabido la peseta no sería moneda base hasta 1868], con atractivos incentivos de sorteos-loterías anuales a los primeros inversores. Su texto es muy interesante pero nos aleja del objeto de este artículo (cfr. Diario de Barcelona, 19-X-54, n 291: 7.299-7.300; reimpreso en idem, 13-XI-54, $\mathrm{n}^{\circ}$ 316: 7.981; PAREDES, 1982: 249-50 y 296, n. 97; GARCÍA-BELLIDO, 2005b: 37-43).

§22. La intervención de MADOZ en el tema de las murallas no puede entenderse aislada de la inestabilidad política y laboral que, incluso, llega a explicar su papel decisivo que supo jugar como político. El paro y las huelgas son paliados en parte mediante el trabajo que ofrece el derribo de aquellas murallas; pero el dinero para pagar a los parados que ejecutan la demolición, precisamente, es financiado con el urbanismo... solución que sería impulsada y teorizada hasta el rango de una nueva disciplina por esa mente creadora que sabe elevar la oportunidad a categoría científica: el ingeniero CERDÁ.

Esta es en esencia la clave para entender esta encrucijada de hechos y oportunidades fortuitos de entre los que nacería el urbanismo moderno. Su novedad respecto a los diez mil años anteriores de la historia universal reside en el protagónico papel de la gestión coordinada público-privada entre poderes con derechos jurídicos reconocidos y capitales privados disponibles: revolucionaria coyuntura jurídico-política sólo posible desde entonces por derivar necesariamente del constitucionalismo del liberal Estado de Derecho.

§23. El 22 de octubre de 1854 MADOZ abandona definitivamente Barcelona para irse a tomar posesión en las nuevas Cortes constituyentes e iniciar un año que le llevará al cenit de su carrera política: la cartera de Hacienda (21 enero-5 de junio 1855) desde la que en cinco meses podrá elaborar e impulsar la Ley General de Desamortización.

Le sucederá en el puesto de Gobernador civil de Barcelona Cirilo FRANQUET (que lo ocuparía desde el 22 de octubre del 1854 hasta el 13 de julio del 55), personaje de verdadera relevancia en el futuro del urbanismo barcelonés; quien, al poco de tomar posesión y en diligente cumplimiento de una RO del Ministro de la Guerra del 26 de octubre (parece que convocada como reafirmación de la jurisdicción militar en el asunto, tras el "gol" de la ROC de 6 de octubre) para formar una Comisión mixta civil y militar con el objeto de estudiar el ensanche,

\footnotetext{
${ }^{9}$ Según el Diario de Barcelona de 19-X-54 (DB, $\left.\mathrm{n}^{\circ} 291: 7.298\right)$, el Ministro de Hacienda comunicaba al Gobernador civil de la provincia, Excmo. Sr. D. Pascual Madoz, el beneplácito de la Reina al levantamiento "de un empréstito con la hipoteca especial de los terrenos de las murallas y sus glacis" propuesto por el mismo Pascual MADOz en fecha 17 de septiembre de 1854 [documento no hallado aún]. Así mismo se aprueba la petición del Ayuntamiento constitucional de Barcelona que se abonen por cuenta del Estado las cantidades invertidas y las que se inviertan en adelante en el derribo de las murallas de la misma. Le sigue la publicación íntegra del proyecto de empréstito.
} 
diez días después, el 5 de noviembre nombra a CERDÁ Ingeniero civil de la Hacienda Pública de Barcelona y nueve días después, el 14 de noviembre le nombra miembro de dicha Comisión mixta que se constituye el $21\left({ }^{10}\right)$, para tres semanas después, el 16 de diciembre "comisionar a CERDÁ para hacer el plano de los alrededores de Barcelona" $\left({ }^{11}\right)$, puerta de entrada absolutamente decisiva de la poderosa figura de CERDÁ en el urbanismo y que marcará en adelante, no solo el urbanismo universal, sino la propia vida de CERDÁ. Pocos días después Cerdá recibe el nombramiento de Comandante del Batallón de Zapadores de la Milicia Nacional, garantía de su pertenencia activa al partido liberal, y el mismo mes fue elegido síndico del nuevo Ayuntamiento de Barcelona.

Las relaciones o vínculos de MADOZ con su sucesor FRANQUET, que impulsaría con entusiasmo, como luego veremos, el empréstito levantado por MADOZ, y de FRANQUET con CERDÁ, para tomarlo como apoyo a su decisiva política de impulsor del ensanche frente a los ingenieros militares, es para mí desconocida. Sabiendo que MADOZ y CERDÁ ya se conocían como correligionarios desde 1851, al menos [vide ut supra §5], no es impensable que MADOz le hablara a FRANQUET de Cerdá y les presentara personalmente, al fin y al cabo hombre de su plena confianza partidaria, para levantar los planos del terreno y proyectar el trazado del ensanche, imprescibdibles ambos para desembarazar el empréstito y digerir la patata caliente que MADOZ dejaba en manos de FRANQUET.

§24. Cuando ya se habían subastado casi todos los terrenos del Estado y en parte edificado, según el plano de CERDÁ aprobado por el Gobierno en 1859, al arquitecto municipal de Barcelona, Miquel GARRIGA I RoCA (autor del plano de "cuarterones" de la Ciutat Vella, mientras CERDÁ hacía el del Pla exterior, y quien presentaría seis soluciones del Ensanche al concurso del Ayuntamiento de 1859; ver infra §30, nota 17), se le ocurre un 19 de abril de 1861 modificar el Plan de Cerdá, ya definitivamente aprobado por el Gobierno, y proponer un gran boulevard de ronda de la Ciutat Vella de $60 \mathrm{~m}$ de ancho con edificios públicos y representativos (a imagen de los parisinos o del Ring vienés o berlinés), que bajará a $45 \mathrm{~m}$ en 1862, frente a las calles de sólo $30 \mathrm{~m}$ exiguos que tenía en el plano oficial de CERDÁ $\left({ }^{12}\right)$.

Tras múltiples forcejeos, presiones, reacciones, contrapropuestas e inundaciones por medio (incluso represalias profesionales contra CERDÁ por oponerse en redondo, además de por razones funcionales de su proyecto de transición sin solución de continuidad de un tejido a otro, sin cesuras, por la necesidad de hacer el gran colector de aguas del Pla) y con la dura oposición de los tenedores de las cédulas hipotecarias y de los que ya habían adquirido el suelo edificable densificado de aquellos terrenos $\left({ }^{13}\right)$, quedaría definitivamente desde 1865 en una estrecha ronda canalizando la 'gran cloaca colectora' del alcantarillado del ensanche, como lo había diseñado CERDÁ (cfr. GIMENO \& MAGRINYA, 1994; MAS, 1999: 68-71; CAPEL, 2002: I: 150-3).

\footnotetext{
${ }^{10}$ Quedando formada por Ildefonso CERDÁ, por parte del Ministerio de Gobernación o Gobierno civil, por el Teniente Coronel graduado, Capitan del Cuerpo de Ingenieros militares, Salvador ARIzON (cfr. informe de la Comisión mixta del Ensamche de 19-XII-54 en el AGMS, 3a/3a/Leg. 138; §A-22/54) por parte del Minsterio de Guerra, y por el arquitecto Antonio ROVIRA Y TRÍAS, por el Ayuntamiento.

${ }^{11}$ En dicho encargo, FRANQUET dispone que CERDÁ le "proponga el personal y lo necesario para principiar el día 18 las operaciones del levantamiento de los planos preparatorios para el ensanche" (sic. CERDÁ, ICr); trabajo que CERDÁ pidió hacer gratuitamente, como recordará en el propio texto de su Memoria del Anteproyecto (CERDÁ, 1855, MAEB: §§6-8), aunque luego jamás se le agradeciera (CERDÁ, c. 1874, Des: § 9).

${ }^{12}$ Ver GIMENO \& MAGRINYA (1994: 172-7), que describen con gran detalle este episodio, aunque sin conectarlo con los intereses de los tenedores de las cédulas hipotecarias y terrenos que no aceptan mermar sus expectativas; cfr. planos en Mostra Fons MuniCIPAls (1985: 143-5, refs. 12411, 12413 y 12414 de CeRdÁ); CaTAlOg. EXP. "Abajo las murallas..." (2004: 91, no 89).

${ }^{13}$ Ver el plano ref. 12414 de CERDÁ, de 22-VI-1865 en MOSTRA FONS... 1985, del ArchMunicAdm PC: 22: 8, con los solares vendidos y por vender (cfr. GIMENO \& MAGRINYA, 1994: 172-7).
} 


\subsection{Y, como consecuencia, el plano base de CERDÁ para el ensanche de Barcelona y su agria polémica profesional.}

$\S 25$. Desde el momento en octubre de 1854 en que se sabe que, con MADOZ al frente, las murallas van a derribarse definitivamente, se inicia el período crítico de cinco a seis años (1854-1860) en que se elaborarán los planos cartográficos de base del Pla extramuros y de la ciudad interior, se inician comisiones de expertos, viajes y gestiones sin cuento para decidir cuáles han de ser las bases de los ensanches de las poblaciones (preparatorios de la legislación de Ensanches de 1861 —non nata- y 1864), propuestas de francotiradores de cómo hacerlo en concreto para Barcelona, idas y venidas a Madrid para intrigar y contrarrestar, etc. en un palpitante período que, desde la conferencia de F. PUIG I ALFONSO, en 1915, con su "Génesis del Ensanche de Barcelona" y la resonancia que le confiere ESTAPÉ (1971: III: 213-37) a la tramitación del expediente del ensanche no ha dejado de ser narrado y comentado múltiples veces, en libros, jornadas y exposiciones (cfr. per alia, GIMENO, 1994; SAGARRA, 2004).

Una pincelada para situar al lector en aquellas circunstancias en las que, en nuestro intento de conectar este proceso vital para el urbanismo español con MADOZ, han de mencionarse dos momentos en que vuelven a cruzarse las vidas profesionales de MADOZ y CERDÁ.

§26. Los trabajos cartográficos del Pla de Barcelona que CERDÁ finalizará antes de un año de haberlos empezado (el 18 dcbre 1854; cfr. supra §23), en noviembre de 1855 y remitirá en esos meses sendas copias con su Memoria (fechada el 16 de dcbre.) y Atlas del anteproyecto del Ensanche al Ministerio de Fomento de Madrid, al Ayuntamiento de Barcelona y al propio Gobernador FRANQUET que se lo encargara $\left({ }^{14}\right)$. En concreto, el 7 de diciembre de 1855 consta que el Ayuntamiento envía también por su cuenta a la Junta Consultiva de Caminos, Canales y Puertos, órgano técnico supremo consultivo del Estado en el Ministerio de Fomento, el mismo

"plano de los alrededores de Barcelona, que había mandado levantar, acompañado del dictámen de las Corporaciones é Institutos de esta Ciudad sobre las bases que debian tenerse presentes para su ensanche, de un anteproyecto relativo al mismo objeto y una

\footnotetext{
${ }^{14}$ Lo que explicaría que esa segunda copia de amanuense de esta su primera obra escrita, Ensanche de la Ciudad de Barcelona. Memoria descriptiva ... en la formación del Ante-proyecto para el emplazamiento y distribución del Nuevo Caserío (abrev. MAEB, 1855) acabase en manos de los herederos de la familia de Cirilo FRANQUET, y en particular del que fuera mucho después alcalde de Barcelona, José FRANQUET Y DARA, Barón de Purroy (1844-1927). Además del 23 de nov., también registra Cerdá que el 31 de enero del 56 recibe y contesta un oficio del Gobernador "acerca de la terminación de la $2^{\mathrm{a}}$ copia (sic) de los planos del ensanche y demás extremos que le pide el Ministro de Hacienda" [que ya no era MADOZ desde hacía 8 meses] ¿Es que mandó hacer otra segunda copia de los planos para Hacienda? Porque un mes después vuelve a verse que el mismo Gobernador le manda otro oficio a CERDÁ "reclamando el duplicado del plano de los alrededores y comunicación pasada con este motivo al Ministro de Hacienda" (Por ende: ¿existirá otra copia del plano de CERDÁ en el Ministerio de Hacienda, aun no hallada?) Lo que sí estamos en condiciones de afirmar es que CERDÁ mandó hacer dos copias manuscritas iguales del texto de la MAEB: una se halló en el AGA junto al Proyecto y la TCC, las Ordenanzas de Barcelona de 1859 y la Teoría de la Viabilidad Urbana de Madrid de 1861 (que fueron editados íntegramente por mí en el INAP en 1991); y otra segunda copia parece ser es la que fuera a manos de los herederos de FRANQUET, quienes ahora lo han vendido, según me comentan, como manuscrito original de anticuario, y tras intentarlo con las instituciones posibles de Cataluña, por la disparatada cantidad de ciento cincuenta mil euros, a través del librero Luis CRESPí DE VALLDAURA, de Madrid, a la propia Biblioteca Nacional con Rosa Regás en su dirección. Es penoso seguir las vicisitudes de algunos documentos históricos que las familias herederas convierten en tesoros especulativos, como le ocurrió al Legado Cerdá que adquiriera, al fin de un triste peregrinar, el Colegio de Ingenieros (cfr. MAGRINYÀ \& GIMENO: "Addenda [a la 'Biografía de Cerdá']: 'A propósito del legado Cerdá', en CATÁlogo EXPOSICIÓN..., 1994-98: 152-3).
} 
estensa y minuciosa memoria estadística que forma la base esencial de esta publicacion" [que es la MAEB] (CERDÁ, 1859: TCC: $§ 591 ; I C r)\left({ }^{15}\right)$.

$\S 27$. Desde ese final de 1855 , en que se tiene el plano de los terrenos del llano barcelonés, y los tres años siguientes, al final de 1858 se suceden varias propuestas de planos del ensanche de Barcelona -como los de Juan MAÑÉ Y FLAQUER, las del arquitecto municipal GARRIGA I ROCA, la de J. Francesc SOlER I GLORIA, etc. (CERDÁ, ICr: 27-III-58; idem: VII-58; ESTAPÉ, 1971: 355-70; GIMENO, 1994; SAGARRA, 2004)— que pretenden desplazar o enmendar el del MAEB de CERDÁ de 1855, que era el que circulaba por las esferas del poder central.

Hasta que -ya con la reacción, frente al "Bienio progresista", de los gobiernos alternantes de O'DONNELL / NARVÁEZ desde julio de 1856- llegaron por fin las Reales Ordenes de 29 de octubre y 9 de diciembre de 1858, bajo el gobierno del primero, por las que los militares al decidir que Barcelona no sea plaza fuerte bajo tutela militar — liberándola efectivamente de la carga de la zona militar o polémica de protección-servidumbre que impedía cualquier desarrollo urbano en las propiedades privadas del llano extramuros y por tanto bloqueaba el ensanche - se desentienden competencialmente de sus murallas y fortalezas restantes y de sus terrenos afectos en el ensanche, pasándole la competencia (no la propiedad) en todos los asuntos relacionados con ello al de Fomento y asumiendo el Ayuntamiento la gestión o ejecución de las obras de urbanización. Lo más importante desafectando a la ciudad de Barcelona de su condición y servidumbre de plaza fuerte

Lo cual disparará y acelerará en una carrera frenética los trabajos del Ayuntamiento que propone a toda prisa convocar una Comisión Consultiva más, con el objeto de ver cómo hacer el ensanche.

$\S 28$. Aquí vuelven a cruzarse el MADOZ ya ex-ministro, pero con influencias, y el CERDÁ intrigante que anda sumido en las peripecias del ensanche de Barcelona, viajando entre ésta y Madrid.

Precisamente para aclarar el alcance y significado de lo que esa R.O. de 9 de diciembre implicaba, el Ayuntamiento al mes siguiente, en enero de 1859, encarga a tres diputados a Cortes por Cataluña -a saber: a Laureano FIGUEROLA (economista e insigne precedente estadístico de MADOZ y CERDÁ; ver supra §14), a nuestro Pascual MADOZ y a Jaume BADíA-, que gestionen 'lo' del ensanche ante el Ministerio (ESTAPÉ, 1971: 214-5).

De esta comisión de gestiones ministeriales el diario de CERDÁ no dice nada. Las gestiones que CERDÁ haría en Madrid ese mismo mes serían decisivas para su futuro, probablemente a escondidas de esa Comisión de diputados...

§29. Y la segunda vez que se encuentran, es ya físicamente en Madrid, en torno al Proyecto final de CERDÁ para el Ensanche y reforma de Barcelona. Es el propio CERDÁ esta vez quien nos cuenta en su Diario (ICr, 1815-1875: abril 1859) que en su viaje a Madrid con LLASERA y

\footnotetext{
${ }^{15}$ Sería todo este envío del material del Anteproyecto del Ensanche de Barcelona a la Junta Consultiva de Caminos, en especial la Memoria o MAEB lo que consultaría y copiaría, a veces literalmente, Carlos María DE CASTRO, ingeniero y arquitecto, recién llegado encargado del Ensanche de Madrid (cfr. FRECHILLA, 1999). El Sector Norte del Ensanche de Madrid de CASTRO se aprueba con prisas el 20 de agosto de 1858 (casi un año antes que el Proyecto del de Barcelona: 7 jun. 1859 y completado con ordenanzas y pensamiento económico en septiembre de 1859), aunque el Ante-proyecto de CASTRO del Ensanche completo de Madrid no lo entregaría hasta el 6 de mayo de 1859 y no se aprobaría muy modificado hasta el R.D. de 19 de julio de 1860 (mes y medio después del de Barcelona). No se debe olvidar que este proceso corría paralelo en "saltos de obstáculos" con la consolidación de CERDÁ en la Corte, puesto que el 11 de enero de 1860 CERDÁ solicitaría autorización para hacer los estudios de la reforma interior y mejora de Madrid que le autorizarán al mes por R.O. de 16 de febrero siguiente y que entregará terminada en una muy elaborada Teoría de Viabilidad Urbana de Madrid... (TVU) en enero de 1861 y un duplicado el 10 febrero 1862 (aunque no se aprobará nunca), auténtica charnela fundamental de la historia del urbanismo, sin la que no se llegaría a la Teoría General de la Urbanización (TGU) en 1863, publicada en 1867 (cfr. FRECHILLA, 1999; GARCÍA-BELLIDO, 1999).
} 
HERA, del 12 al veintitantos de abril de 1859 vería personalmente a MADOZ al llevarle el Proyecto del Ensanche de Barcelona.

Este encuentro hay que plantearlo en el contexto de un momento en plena vorágine del debate reivindicativo municipalista que suscita el Ayuntamiento de Barcelona contra el Gobierno central sobre quién tenía la competencia material para aprobar la ordenación de la ciudad futura y de paso - aunque para muchos fue al revés- decidía cuál iba a ser el proyecto definitivo para el Ensanche de Barcelona: si el proyecto de un ingeniero funcionalista, racionalista y monótono, como CERDÁ, o el de los arquitectos artistas de las Bellas Artes con calles curvas y perspectivas barrocas, como las propuestas de GARRIGA o ROVIRA, etc. Por ello el predicamento de CERDÁ en el Ministerio de Fomento inquietaba tanto a los arquitectos barceloneses que movilizaron sus fuerzas para parar los pies al intrigante ingeniero "agrimensor".

$\S 30$. Las espadas entre el Consistorio y el Ministerio estaban en alto desde que CERDÁ, en un viaje a Madrid el 12 de enero de 1859, hubiera obtenido del Ministro de Fomento, Rafael DE Bustos y CAStILLA, Marqués de CoRvera (luego muy amigo de CeRDÁ hasta su vejez), la autorización por R.O. de 2 de febrero de 1859 concediendo autorización á D. Ildefonso CERDÁ para verificar en 12 meses los estudios de ensanche y reforma de Barcelona $\left({ }^{16}\right)$ (cuando ya tenía hecho desde 1855 el plano del Anteproyecto del Ensanche y su MAEB), obteniendo una especie de salvoconducto ministerial de "enterado", pero sin compromiso alguno, a la vez que obtenía la legitimación precisa para presentarse en Barcelona como encargado personalmente por Madrid del proyecto del ensanche ante los diversos contrincantes artistas y propuestas varias que habian estado haciéndose.

Precipitadamente el 12 de ese mismo mes de febrero se constituye una Comisión Consultiva del Ensanche por el Ayuntamiento con 20 personas de variada procedencia (bajo la presidencia del gobernador civil Ignacio LLASERA y con DURÁN Y BAS entre ellas, que era el Secretario General del Ayunt ${ }^{\circ}$ y un erudito) y el 14 de abril publican sus resoluciones, que no acata el Ayuntamiento. Y más precipitadamente aún, al día siguiente 15 de abril, el Consistorio convoca el famoso concurso de proyectos, dando un plazo hasta el 31 de julio (luego prorrogado un mes), fecha en la que precisamente CERDÁ estaba en Madrid $\left({ }^{17}\right)$.

CERDÁ aceleró todo el trabajo al conocer que el Ayuntamiento iba a hacer un concurso para desplazar su proyecto y se lo llevó acabado a las autoridades madrileñas ¡Cómo no estaría ya de acabado y estudiado que un mes y 10 días después de aquella R.O. de 2 de febrero, y diez meses y 20 días antes del plazo (nada de esperar 12 meses), le llevaban a Madrid al propio CORVERA al Ministerio de Fomento, nada menos que la avasalladora Teoría de la Construcción de la Ciudad y el Atlas del proyecto, en una copia manuscrita y encuadernado en piel!, que es lo que seguidamente vamos a ver cómo se cuenta en el Diario de CERDÁ.

\footnotetext{
${ }^{16}$ Ministerio de Fomento.- Obras Publicas.- Construcciones Civiles: "llustrísimo señor: S.M. la Reina (q.D.g.), accediendo á lo solicitado por D.Ildefonso Cerdá, ha tenido á bien autorizarle para que sin perjuicio de los derechos de propiedad, verifique en el término de 12 meses los estudios de ensanche y reforma de la ciudad de Barcelona, debiendo considerarse esta gracia sin derecho á la concesion definitiva de la empresa, si no se estima conveniente, ni á indemnizacion alguna por los trabajos que al efecto practique. De Real órden lo digo á V.I. para su inteligencia y efectos consiguientes. Dios guarde á V.I. muchos años. Madrid 2 de febrero de 1859.- Corvera.-Sr.-Director General de Obras Públicas. (Gaceta núm. 39).

${ }^{17}$ Se presentarían 7 (más 6 variantes de una) propuestas conocidas de los arquitectos A. RovIRA I TRIAS, ganador del concurso con su ensanche octogonal centrípeto, las seis propuestas del arquitecto municipal M. GARRIGA I ROCA, la del arquitecto municipal F. DANIEL MOLINA, la del ingeniero F. SOLER I GLÒRIA, la del arquitecto e ingeniero F. SOLER I MESTRES, y la del maestro de obras J. FonTSERÉ I MESTRES, más la de I. CERDÁ (cfr. ESTAPÉ (1971: 213-37; GIMENO, 1994; SAGARRA, 2004).
} 
$\S 31$. En ese viaje de abril de 1859 a Madrid, y antes de entregar el manuscrito original al Ministerio de Fomento para su examen con tal adelanto, CERDÁ visita para enseñárselo en primer lugar a Cirilo FRANQUET (que ya se ha visto fue el inmediato sucesor de MADOZ en el Gobierno civil de Barcelona en 1854; ver ut supra §23); en segundo lugar a Ignacio LLASERA (Gobernador civil de Barcelona en aquellas fechas de 1859 y presidente de la Comisión consultiva municipal ique acababa de presentar días antes las bases del concurso!); en tercer lugar a Laureano FIGUEROLA (amigo común de MADOZ y CERDÁ; ver ut supra §14) dejándoles repasar el único manuscrito de su preciada obra hasta el 15 abril; y luego, finalmente se lo llevaron a casa de Pascual MADOZ el día 16, quien lo retuvo hasta el 17 , fecha en que lo llevaron a entregar en el registro general del Ministerio de Fomento $\left({ }^{18}\right)$.

Es en este punto donde el diario de HERAS, que encaja perfectamente con el más escueto de CERDÁ, dice sobre este viaje:

"16 abril: Llevamos el proyecto a casa del Sr. Madoz a quien tuvimos que aguardar cerca de una hora. Después de haberle explicado el estado del asunto y de haberle hecho una breve reseña del trabajo que se le presentaba para que lo juzgara, contestó que procuraría enterarse, pero que no tenía tiempo más que muy ligeramente; y en cuanto a lo demás, dijo que conceptuaba no era prudente ponerse en pugna con el Ayuntamiento de Barcelona [prudente consejo de quien fuera gobernador civil], a lo cual le contestó D. Ildefonso [que acababa de ser alcalde mayor de Barcelona con las huelgas de 1855 y el tenso asunto de la bandera] que él no pedía tal cosa, sino que obrase como mejor tuviera por conveniente. Al cabo de una media hora de conversación salimos de su casa dejándole el trabajo hasta las 11 de la mañana del día siguiente" [dado que querían presentarlo la mañana del día siguiente en Fomento para ganar tiempo y lograr su aprobación antes del fallo del concurso municipal].

"17 abril: A las 11 de la mañana volvimos a casa de Madoz a buscar los planos y le encontramos ya de diferente modo de pensar que el dia anterior. No tenía ya los escrúpulos sobre el Ayuntamiento de Barcelona ni cosa parecida; al contrario, preguntó qué era lo que debia hacer para que el asunto tuviera buen éxito y que si había de hablarse al Gobierno ó era necesario hacer cualquier cosa estaba a las ordenes de $D$. Ildefonso. Trabose conversación sobre el trabajo en general y en particular sobre la cuestion obrera y seguimos conversando

\footnotetext{
${ }^{18}$ Piénsese que traían un mismo y único original manuscrito del Proyecto del Ensanche escrito bajo el ambicioso título de Teoría de la Construcción de las Ciudades aplicada al proyecto de reforma y ensanche de Barcelona (TCC)... y los planos del Atlas (desaparecidos), TCC que acabaría hallándose en el Archivo General de la Administración del Estado (AGA) en Alcalá de Henares en 1985, por Pilar RIVAS y Fuensanta MURO, sin que nadie los hubiera ni ojeado desde entonces. Lo normal era hacer una sola copia encargada a un pendolista y planos originales todos en tela, por lo que aprovecharon el viaje cargados con el tomo encuadernado en piel y el desaparecido atlas para enseñárselo a una procesión de amigos, antes de sumirlo en las procelosas aguas de los despachos de la Administración... de los que acabaría perfectamente identificado y custodiado en el magnífico AGA un siglo y cuarto después ( $\mathrm{i}$ !).
} 
unas dos horas que pasaron sin apercibirnos de ello. Tal fue el cambio en el Sr. Madoz el examen del trabajo que le habíamos presentado el dia anterior; en el cual dijo había consagrado varias horas, a pesar de sus preventorias ocupaciones (...)".

$\S 32$. Y por tener un interés para los urbanistas de la época, merece la pena recordar lo que a continuación añade el diario de HERAS sobre aquella visita al Ministerio de Fomento:

"18 abril (...) El mismo día después de haber presentado D. Ildefonso el oficio de remisión [del Proyecto de Ensanche de Barcelona, TCCB] fue a ver al Sr. Clavijo, oficial del mismo ministerio, quien le explicó lo que había pasado asi que nosotros hubimos salido de allí el día anterior, y fue que se reunieron todos, extendieron los planos y pasaron revista de todo junto con el Director general [de Obras públicas, a quien ya le habian visitado el dia anterior] quien después del examen apostrofó al Sr. Castro, Ingeniero encargado del proyecto de ensanche de Madrid [que lo había sido por RD de 8 de abril de 1857 y que no lo entregaría hasta mediados del año siguiente al de este diario, ya en 1860] diciéndole:

- "Esto sí que es un proyecto bien estudiado, Sr. Castro" y todos tributaron los mayores elogios por el trabajo en términos que Clavijo dijo que había promovido una verdadera revolución." (Diario de Heras, insertado en CERDÁ, ICr, 1859: 639; cvas explicativas entre corchetes mías).

Este comentario del Director general en relación con el plan del ensanche de Madrid que estaba haciendo Carlos María de CASTRO, encaja perfectamente con la recepción que éste reconocería haber tenido de las ideas de Cerdá en su proyecto (ver ut supra §26, nota 15).

Entre tanto, la urgencia de CERDÁ en llevar en mano su TCC y el proyecto tendría su premio en recorrer los escalones administrativos con celeridad nunca jamás repetida, ya que el 6 de mayo (¡18 días después de entregarlo!) dictaminaría la Junta Consultiva de Caminos Canales y Puertos, máximo órgano de Fomento, proponiendo aprobar el proyecto de CERDÁ; publicándose su aprobación por la R.O. de 7 de junio (al cabo de un mes y 18 días de meterlo por el registro), en pleno plazo del concurso municipal cuando todos estaban trabajando en él febrilmente... La convalidación y reafirmación vendría antes de terminar el plazo, por R.O. del 31 de julio y su aprobación definitiva al completarse todo por R.D. de 31 de marzo de 1860, autorizando con todas las bendiciones edificar en el ensanche de CERDÁ.

Podríamos decir que la propuesta de CERDÁ arrasó por goleada a todos sus contemporáneos porque hubo en el sitio adecuado y en el momento oportuno un poder político que lo entendió y lo impulsó contra viento y marea. 


\section{BIBLIOGRAFÍA CITADA}

BAHAMONDE MAGRO, Ángel (1992): "Pascual Madoz y la modernización de la ciudad de Madrid: La Peninsular, empresa inmobiliaria, 1861-1883", en GARCíA DELGADO J L (ed., 1992): Las ciudades en la modernización de España. Los decenios interseculares, VIII Coloquio de Historia Contemporánea de España, dirigido por M. TUÑÓN DE LARA, Siglo XXI, Madrid, pp. 379-404.

— \& TORO MÉRIDA, J. (1978): Burguesía, especulación y cuestión social en el Madrid del siglo XIX, Siglo XXI (col. Est. de Historia Contemporánea), Madrid, 274 pp.

BAssols ComA, Martín (1973): Génesis y evolución del Derecho Urbanístico español (18121956), ed. Montecorvo, Madrid.

BENET Josep \& Casimir MARTI (1976): Barcelona a mitjan segle XIX: El moviment obrer durant el bienni progressista (1854-1856), 2 vols., Documents de cultura 9, ed. Curial, Barcelona; 819 +729 (161 il.)

CATÁlogo EXPosición “Cerda, CIUdAd Y TERRITORIO” (1994-96): Mostra Cerdà. Urbs i territori: una visión de futuro, TARRAGÓ I CID, dir.; Generalitat de Catalunya / Fundació Catalana per a la Recerca / Electa, sept. 1994-febr. 1995, Barcelona; $2^{a}$ ed. vers. en español; $3^{a}$ ed. Catálogo Exposición: "Cerdà. Pionero del urbanismo moderno", patroc. Ministerio de Fomento, Madrid, 1998, 381pp.

CATÁlOGO EXPOSICIÓN “ABAJO LAS MURALLAS!!!" (2004): 150 anys de l'endorroc de les muralles de Barcelona, Albert Cubeles comisario, Institut de Cultura, Museu d'Història de la Ciutat, Ajuntament de Barcelona, cat/cast., Barcelona, 2004-5.

CAPEL SÁEZ, H (2002-2005): La morfología de las ciudades. Vol. I: Sociedad, Cultura y Paisaje Urbano; Vol. II: Aedes facere: técnica, cultura y clase social en la construcción de edificios, Ed. del Serbal (col. La Estrella Polar, 37 y 47), Barcelona, $544+656$ pp.

CERDÁ I SUNYER, Ildefonso: Cerdá: Barcelona y Madrid; vol. I: Teoría de la Construcción de las Ciudades. Cerdá y Barcelona [abrev. TCC.C\&B]; vol. II: Teoría de la Viabilidad Urbana. Cerdá y Madrid [abrev. TVU.C\&M]; ed. INAP-MAP y Ayuntamientos de Barcelona y Madrid respect., Madrid, 1991, $692+362 \mathrm{pp}$.

_ (1855): [MAEB] Ensanche de la Ciudad de Barcelona. Memoria descriptiva de los trabajos facultativos y estudios estadísticos hechos de orden del Gobierno y consideraciones que se han tenido presentes en la formación del Anteproyecto para el emplazamiento y distribución del nuevo caserío, firmado por I. Cerdá, 16 de Diciembre 1855; transcrito en q.v. TCC.C\&B, vol. I, pp. 51-106.

(1859): [TCC] Teoría de la Construcción de las Ciudades aplicada al Proyecto de Reforma y Ensanche de Barcelona, firmada, abril 1859; dos volúmenes manuscritos (I. Parte, Analítica; II. Parte, Sintética) y atlas, con numerosos dibujos y 37 láms de planos; transcrito en q.v. TCC.C\&B, vol. I, pp. 107-455.

(1861): [TVU] Teoría de la Viabilidad Urbana y Reforma de la de Madrid. Estudios hechos por el Ingeniero D. Ildefonso Cerdá, autorizado al efecto por Real Orden de 16 de Febrero de 1860. Madrid y enero de 1861; dos tomos manuscr. y atlas 17 planos grabados y coloreados; transcr. en TVU.C\&M, vol. II, ed. INAP y Ayuntamiento de Madrid, Madrid, 1991, pp. 45-280.

_ (1861): [CPM] "Cuatro palabras más sobre dos palabras que don Pascual de Uhagón ha dirigido à los propietarios de los terrenos comprendidos en la Zona de Ensanche de Madrid, dedicados á los mismos por don Ildefonso Cerdá", 29 noviembre 1861; reprod. en ESTAPÉ (1968-71), q.v. vol. III, pp. 627-653; y reprod. en q.v. TVU. C\&M, vol. II, pp. 281-289.

(1867): [TGU] Teoría General de la Urbanización y aplicación de sus principios y doctrinas a la reforma y ensanche de Barcelona, etc., 2 vols. Imp. Española, Madrid, 1867 [desconoc.

ACE, Vol.1, núm. 1, pp.4-28, 2006 | PASCUAL MADOZ E ILDEFONSO CERDA, DOS PIONEROS EN LA EPIFANIA DE LA URBANISTICA 
vol. III, atlas (?)]; reimpr. facsímil en Teoría General de la Urbanización, vols. I y II, edit. por ESTAPÉ, IEF, Madrid, 1968.

(1868): Monografía estadística de la clase obrera de Barcelona en 1856, Imp. Española, Madrid, 1868. Apéndice de la TGU, q.v. vol. II, de la que Cerdá hizo una edición y tirada aparte.

_ (1815-1874 y 1874-75): [ICr] «Índice cronológico» de su diario, de 1815 a 1874; y [Dia] «Diario», de enero a noviembre de 1875 (incl. carta al Marqués de Corvera, $c M C$ ) ambos editados en q.v. TCC.C\&B, vol. I, pp. 633-656.

(1869-1875?): [Des] "Despojos. Reclamación contra el despojo que por la Ley de Ensanches se ha hecho de mi plan económico", cuaderno de notas, $1^{a}$ ed. en q.v. TVU.C\&M, Madrid, 1991.

DE SETA, Cesare \& Jacques LE Goff (eds., 1989): La città e le mura, G. Laterza \& Figli Spa., Roma-Bari; vers. esp. C. Borra: La ciudad y las murallas, Cátedra, Madrid, 1991; 399 pp.

DicCIONARIO GEOGRÁFICO DE ESPAÑA (1956-1961): Germán BLEIBERG, director; introd. Rafael SÁNCHEZ MAZAS, 17 vols.; edic Prensa Gráfica, SA (t. 1), Madrid, y Edic. del Movimiento (t. 2 a 17), Madrid, 1957-1961.

ESTAPÉ, Fabián (1971): "Estudio sobre la vida y obra de Ildefonso Cerdá", en Teoría General de la Urbanización, vol. III: Vida y obra de Ildefonso Cerdá. Bibliografía y Anexo documental, IEF, Madrid, pp. 11-316.

FRECHILLA CAMOIRAS, Javier (1999): "Seis episodios en la redacción del anteproyecto de ensanche de Madrid", CYTET, vol. XXXI, n 119-120, pp. 273-291; reed. en q.v. GARCíABELLIDO (dir. 2004), pp. 277-295.

GARCÍA-BELLIDO Ga DE DIEGO, Javier (1994): "Inicios del lenguaje de la disciplina urbanística en Europa y difusión internacional de la "urbanización" de Cerdá", en Anales de Historia del Arte, núm. extraord. (Tiempo y Espacio. Homenaje al Profesor Antonio Bonet Correa), vol. II, pp. 1.103-1.144.

(2000): "Ildefonso Cerdà y el nacimiento de la Urbanística: la primera propuesta disciplinar de su estructura profunda", Scripta Nova. Revista Electrónica de Geografía y Ciencias Sociales, vol. IV: $\mathrm{n}^{\circ}$ 61, 1 de abril de 2000, Universidad de Barcelona [http://www.ub.es/geocrit/sn-61.htm]

- (dir., 2004): Cerdá y su influjo en los ensanches de poblaciones, Dir. Gral Vivienda, Arquitectura y Urbanismo (Serie Monografías), Ministerio de Fomento, Madrid, $413 \mathrm{pp}$. Reedición del n. ${ }^{\circ}$ monograf. doble de CyTET, vol. XXXI, $\mathrm{n}^{\circ}$ 119-120, 1999, con bibliografía compilada.

- (2005a): «Propuesta para la configuración de una Teoría General de la Gestión Urbanística», Geo Crítica / Scripta Nova, Revista electrónica de geografía y ciencias sociales, Barcelona: Universidad de Barcelona, 1 de septiembre de 2005, vol. IX, núm. 196. http://www.ub.es/geocrit/sn/sn-196.htm

- (2005b): «Prolegómeno: Madoz en los albores de la política urbanística y territorial del siglo XIX», en q.v. MORALES \& alia, eds., 2005: Pascual Madoz...: 19-50.

— \& Sara MANGIAGAlLI (2006) «Pascual Madoz y el derribo de las murallas en el albor del Eixample de Barcelona», comunicación al IX Congrés de d'Història de Barcelona, Institut de Cultura: Arxiu Històric de la Ciutat, 29, 30 nov. y 1 dcbre 2005, Barcelona (en prensa)

GIMENO, Eva (1994): "La gestación del ensanche de Barcelona: el concurso municipal de proyectos de 1859", en q.v. CATÁL. EXPO. Mostra Cerdá..., pp. 155-166.

_ \& MAGRINYA, Francesc (1994): "La intervención de Cerdà en la construcción del Ensanche", en q.v. CATÁL. EXP. Mostra Cerdá..., pp. 167-188.

GRAU, Ramon \& Marina LÓPEZ GUALLAR (coords. 1988): Exposición Universal de Barcelona. Libro del centenario 1888-1988, ed. Comisión Ciudadana para la conmemoración del

ACE, Vol.1, núm. 1, pp.4-28, 2006 | PASCUAL MADOZ E ILDEFONSO CERDA, DOS PIONEROS EN LA EPIFANIA DE LA URBANISTICA 
centenario de la Exposición Universal de Barcelona del año 1888 y L'Avenç, S.A. Barcelona, $570 \mathrm{p}$.

MAGRINYA TORNER, Francesc (2003): La théorie urbanistique d'lldefons Cerdá et son application à l'ensanche de Barcelone : une genèse d'urbanisme de réseaux, 2 vols., tes. doct. ined., ESICCP-UPC.

MAS HERNÁNDEZ, Rafael (1999): "La promoción inmobiliaria en los ensanches del siglo XIX", CyTET, vol. XXXI, $n^{\circ}$ 119-120, pp. 55-73; reed. en q.v. GARCÍA-BELLIDO (dir. 2004), pp. 5573.

(2003): La presencia militar en las ciudades: orígenes y desarrollo del espacio urbano militar en España, Los Libros de la Catarata \& Servicio de Publicaciones Universidad Autónoma de Madrid, Madrid; 251p.

Morales, Guillermo \& Javier GARCíA-BelLIDO \& Agustín DE Asís (eds., 2005): Pascual Madoz (1805-1870) Un político transformador del terriotrio. Homenaje en el bicentenario de su nacimiento, Instituto Pascual Madoz-Universidad Carlos III de Madrid; 231 pp.

MOSTRA FONS MUNICIPALS (1985): Inicis de la urbanística municipal de Barcelona. Mostra del fons municipals de plans i projectes d'urbanisme, 1750-1930, febrero-marzo 1985, direc. TORRES I CAPELL, LLOBEt I BACH \& PUIG I CASTELlS, ed. Ajuntament Barcelona / Corporació Metropolitana de Barcelona, $277 \mathrm{pp}$.

Nicolau I MARTí, Antoni \& CuBELES I Bonet, Albert (2004): "El 150 aniversario del derribo de las murallas: replanteando la ciudad contemporánea", en q.v. CATÁLOG. EXPO. "Abajo las murallas...", pp. 14-37 y 138-147.

PAREDES Alonso, Francisco Javier (1982): Pascual Madoz, 1805-1870. Libertad y progreso en la monarquía isabelina; $2^{\mathrm{a}}$ ed.: Ediciones Universidad de Navarra, SA (EUNSA), Pamplona, 1991, 574 pp.

Pinto CRespo, Virgilio \& MAdRAzo Madrazo, Santos (dirs., 1995): Madrid. Atlas histórico de la ciudad. Siglos IX-XIX (vol. I); PINTO (dir., 2001): Idem: 1850-1939 (vol. II) con prólogo de Miguel ARTOLA; ambos ed. Centro de Documentación y Estudios para la Historia de Madrid, UAM, \& Fundación Caja de Madrid / Lunwerg, Madrid, 430 + 514 pp.

QUIRÓS LINARES, Francisco \& Jacobo GaRcía ÁlVAREZ (2005): »Pascual Madoz y la lectura del territorio: el Diccionario Geográfico y el Atlas de España y sus Posesiones de Ultramar», en q.v. MORALES \& alter: 53-70.

SORIA Y PUIG, Arturo (1979): Ildefonso Cerdá, hacia una teoría general de la urbanización, ed. CICCyP / Turner, Madrid, 229 pp.

SAgARRA I TRIAS, Ferrán (2004): "Les idees per a l'Eixample", en q.v. CATALOG EXPO "Abajo las murallas...", pp. 84-95 y 167-171.

TARRAGó, Salvador (1992): "Quadricular la terra", en LUB (compil. 1992): Treballs sobre Cerdà $i$ el seu Eixample a Barcelona / Readings on Cerda and the Extension Plan of Barcelona: 146-55, Ayuntamiento de Barcelona y CEHOPU (MOPT), Barcelona, 393 pp.

TUÑón DE LARA, Manuel (1960): La España del siglo XIX; $4^{\text {a }}$ ed.: Ed. Laia, Ediciones de Bolsillo, Barcelona, 1973, $438 \mathrm{pp}$. 